\title{
For Undergraduate Researchers
}

\author{
C.C. Chancey, Editor \\ American Journal of Undergraduate Research \\ University of Northern lowa \\ Cedar Falls, lowa 50614-0150 USA
}

\section{WHY PUBLISH?}

Let's assume you're an undergraduate who did some research. Your research advisor said you did a good job, so you gave a talk or presented a poster at your college's annual undergraduate symposium. Maybe you even presented your research at a regional or national conference. You enjoyed your research project, and you learned a few things about scientific communication in preparing for and giving your presentation. Why go a step further to write a research paper?

There are a number of reasons for writing up your research: 1) personal notoriety, 2) a wider dissemination of the research, 3) practice with writing, 4) to obtain professional commentary on your research, and 5) to open channels of communication with other undergraduate researchers.

\section{NOTORIETY}

The first of these might be thought too venal for consideration, but it is not unworthy to wish to have your name associated with well-done research. It is both appropriate and practical. Your research paper is a public recommendation on your behalf to future admittance committees and employers. It speaks to your ability to organize your research results in a concise and informative format.

\section{DISSEMNIATION}

Gaining a wider dissemination for your research provides the opportunity for it to be understood within the context of international research in your area. Science progresses by the free exchange of ideas, and your work-small though it might seem-is part of the currency of scientific progress.

\section{PRACTICE WRITING}

Scientific research papers are distinct from other types of writing that most undergraduates are familiar with, such as textbooks and class essays or term papers. Most research papers provide only brief reviews of the scientific literature on which they build. Research writing is concise and makes strategic use of previously published research. Long expository background sections are usually reduced to a couple of sentences with references. The longest sections of the paper are typically reserved for research methods or research assumptions and results. Learning to write clearly and to the point are important skills which research writing promotes, and to write well takes "on the job" practice.

\section{PROFESSIONAL COMMENTARY}

Scientific research can often be improved, in substance and/or presentation, through the review process common to science. Professional researchers read and comment on the work of other researchers. This is done anonymously to allow reviewers complete freedom of expression. These comments are provided to the original researcher, who can agree or disagree (with cause). All this is done with the aim of improving the research paper before it reaches publication.

\section{TO OPEN CHANNELS}

One of the professional pleasures of being a researcher is meeting other researchers and learning about their work, especially if it is closely related to our own. 
As an undergraduate author, you have the opportunity to connect with other researchers interested in your work and to learn about their interests. Many friendships between scientists of different countries or
Cultures are founded on research collaborations that begin with a published paper.

Why publish? Given all these reasons the response must be: Why not?

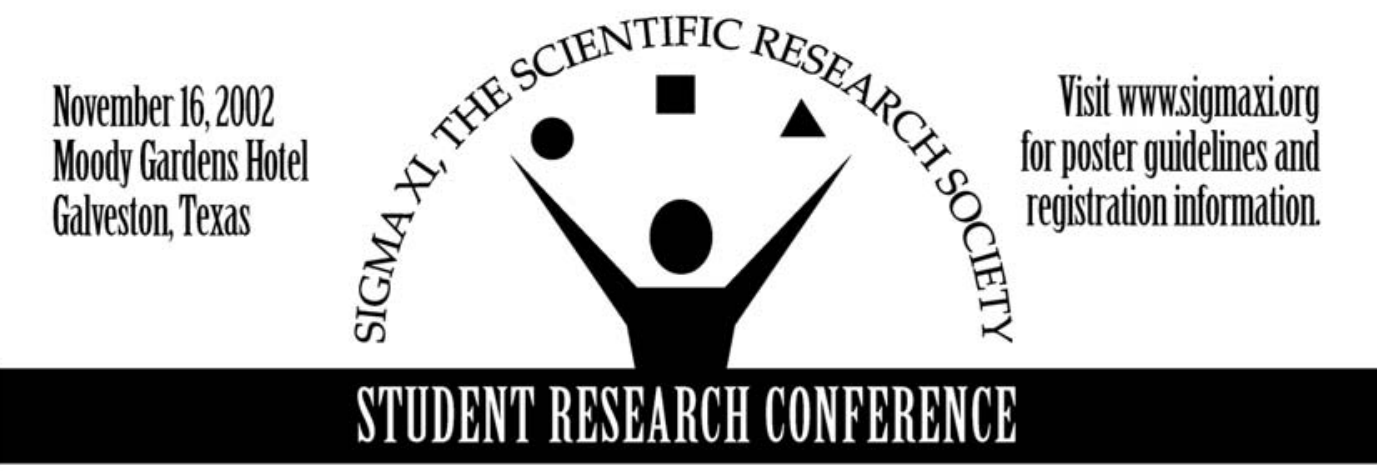

\section{Sigma Xi Student Research Conference Peatures 'Tak by Benoit Mandelebrot}

A talk by internationally renowned mathematician Benoit Mandelbrot, the creator of fractal geometry, is among the highlights of the 2002 Sigma Xi Student Research Conference at Moody Gardens Hotel, Galveston, Texas, Saturday, November 16.

October 4 is the deadline for high school and undergraduate student poster proposals. For guidelines and registration information, visit www.sigmaxi.org.

Cash awards will be offered for the most outstanding posters. During the day, students will also have a chance to interact with leading researchers from across the country and around the world. The student research conference is being held in conjunction with Sigma Xi's annual meeting and forum (November 15-17), which will bring together leading scientists, engineers, educators and policy-makers, as well as government and industry officials.

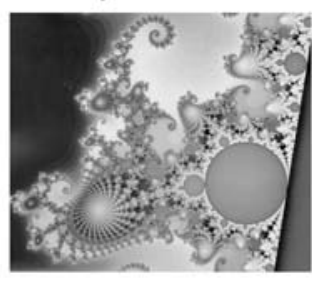

Mandelbrot's fractals have found applications in such diverse fields as physics, economics, the earth sciences and linguistics, capturing the imagination of artists, scientists and the public. A professor at Yale University, he will receive Sigma Xi's 2002 William Procter Prize for Scientific Achievement.
Throughout the day in Galveston students will be able to attend special workshops and plenary sessions, including:

The Beauty of Mathematics: Benoit Mandelbrot's originality in mathematics has given birth to entire disciplines. The colorful symmetry of computergenerated fractals also has had a major impact on art and the public's appreciation for mathematics. Communicating Science: American Scientist Editor-in-Chief Rosalind Reid will help students improve their written and oral communication skills. The magazine recently won a Gold Award for General Excellence from the Society of National Association Publications.

Mentoring Program: Students will have a chance to hand out specially made "business cards" to designated mentors who are leaders in industry, academia and beyond.

Graduate School Student Issues Workshop: What does it take to get admitted? What do graduate schools look for? What should students look for in a graduate school? These and other questions will be addressed.

Sigma Xi Grants-in-Aid of Research Workshop: Students will learn about Sigma Xi's grants program, which for 80 years has been supporting young researchers in all disciplines of science and technology.

Exploring Career Paths in Science and Engineering: A panel discussion with leaders in science and engineering who have pursued traditional and non-traditional career paths. 